\title{
Chronic Lymphoedema and Bone Infarction: Rare Complications of Multiple Segmental Fractures of the Lower Limb in a Young Adult
}

\author{
Ngo Yamben Marie-Ange ${ }^{1,2^{*}}$, Nana Chunteng Theophile ${ }^{3}\left({ }^{\circ}\right.$, Nseme Etouckey Eric $^{1}(\mathbb{D}$, \\ Muluem Kennedy Olivier $^{1}$, Tsiagadigui Tsiagadigui Jean Gustave ${ }^{1}$ (i), \\ Ndongo Mvela Laurent Stephane ${ }^{1,2}$ (D), Manga Alexandre1,2, Guifo Marc Leroy ${ }^{1,4}$
}

${ }^{1}$ Faculty of Medecine and Biomedical Sciences, Department of Surgery and Specialities, University of Yaounde 1, Yaounde, Cameroon ${ }^{2}$ National Center of Rehabilitation of Disabilities Persons, Yaounde, Cameroon

${ }^{3}$ Faculty of Health Sciences, Department of Surgery, University of Buea, Buea, Cameroon

${ }^{4}$ Teaching Hospital of Yaounde, Yaounde, Cameroun

Email: *marieyamben@gmail.com

How to cite this paper: Marie-Ange, N.Y., Theophile, N.C., Eric, N.E., Olivier, M.K., Gustave, T.T.J., Stephane, N.M.L., Alexandre, M. and Leroy, G.M. (2022) Chronic Lymphoedema and Bone Infarction: Rare Complications of Multiple Segmental Fractures of the Lower Limb in a Young Adult. Open Journal of Orthopedics, 12, 79-84. https://doi.org/10.4236/ojo.2022.123009

Received: January 16, 2022

Accepted: March 5, 2022

Published: March 8, 2022

Copyright $\odot 2022$ by author(s) and Scientific Research Publishing Inc. This work is licensed under the Creative Commons Attribution International License (CC BY 4.0).

http://creativecommons.org/licenses/by/4.0/

\begin{abstract}
Multiple segmental fractures of the lower limbs, common in developing countries, are the prerogative of Road Traffic Accidents (RTA) involving two-wheeled vehicles. Their management is difficult, associated with complications, and is most often based on a two-stage strategy: Damage Control Orthopaedics, followed by delayed internal osteosynthesis. The aim is to allow early functional rehabilitation and rapid recovery of patients. We report the case of a 39-yearold man, bike rider, after his RTA, presented with segmental homolateral fractures of the femur and two bones of the left leg. Short-term evolution was marked by the appearance of significant lymphedema and bone infarctions of the lower left limb necessitating a transfemoral amputation. Through this observation, the authors highlight the problems related to the complexity of the management of multiple segmental fractures of the lower limb by emphasizing two posttraumatic complications rarely described but to be feared: chronic lymphedema and bone infarction.
\end{abstract}

\section{Keywords}

Lymphœdema, Multiple Fractures, Bone Infarction, Amputation, Damage Control Orthopaedic

\section{Introduction}

Multiple segmental fractures of the lower limbs are common in developing coun- 
tries, accounting for $9.1 \%$ to $25 \%$ of admissions in surgery units [1] [2] [3]. Road Traffic Accidents (RTA), found in $78 \%$ to $90 \%$ of cases, represent the main etiology [3] [4]. They are characterized by the simultaneous occurrence of at least two fractures on different anatomical segments of the lower limb [3] [4]. They often affect young adults and two-wheeled vehicles which are involved in the majority of cases [1] [2] [3]. When these fractures occur in the context of polytrauma, rapid medical resuscitation and Damage Control Orthopaedics (DCO) are indicated in the initial phase in order to restore normovolemia and to stabilize temporarily these fractures in an emergency. The final management must be adapted to avoid the most often feared complications especially infections, complications of prolonged decubitus, bone healing disorders and joint stiffness. In the literature, few studies report lymphedema and bone infarction as complications of long bones fractures [5] [6] [7]. Defined as a chronic progressive pathology characterized by fluid inflation in the lymphatic system, lymphedema is mainly the infectious etiology (filariasis) in the world, cancerous in the Europa but in developing countries, few data exist [6]. Lymphedema secondary to a fracture is a rare complication, accounting for $2.26 \%$ of all limb lymphedema [5].

Post-traumatic bone infarction, rarely described in the literature [7], is defined as osteonecrosis secondary to high-energy trauma located at the diaphyses and metaphyses (as opposed to epiphyseal osteonecrosis, more common) [7].

Through this observation, the authors want to share the difficulties encountered in the management of a case of multiple segmental fractures of the lower left limb in a young man by emphasizing two rare but serious post-fracture complications: bone infarction and chronic lymphedema.

\section{Case Report}

This is a 38-year-old man patient, motorcycle rider, obese, with no other relevant past medical history, admitted in the emergency unit for polytrauma, 30 minutes after a RTA. While riding on his bike, he was reportedly hit laterally by a vehicle running at a high speed. The primary survey found signs of cardiovascular collapse (BP 100/60 mmHg, pulse: $103 \mathrm{~b} / \mathrm{m}$ and RR: $28 \mathrm{c} / \mathrm{min}$ ); a mild head injury with a Glasgow coma scale at $15 / 15$ and a left frontoparietal laceration of $5 \mathrm{~cm}$, left lung dullness, two lacerations with loss of cutaneous and muscular tissue on the antero-medial and lateral aspects of the left thigh, an antero-lateral semicirconferential wound, with a loss of tendinous, muscular and bone tissue at the distal 1/4 of the left leg. An Echo-FAST, standard X-rays of the entire spine, pelvis, chest and left lower limb done at the bedside of the patient and a biological assessment let to a diagnostic conclusion of a left hemothorax of medium abundance, severe anemia ( $\mathrm{Hb}$ at $6.9 \mathrm{~g} / \mathrm{dl}$ ) and multiple segmental fractures of the left lower limb (Figure 1); associating a closed pertrochanteric fracture, open mediodiaphyseal and supracondylar fractures of the femur classified Gustilo-Anderson (GA) IIIA, open mediodiaphyseal (GA II) and distal quarter (GAIIIB) fractures of the tibia; a trifocal fracture of the fibula, comminutive and open (GA IIIB) 

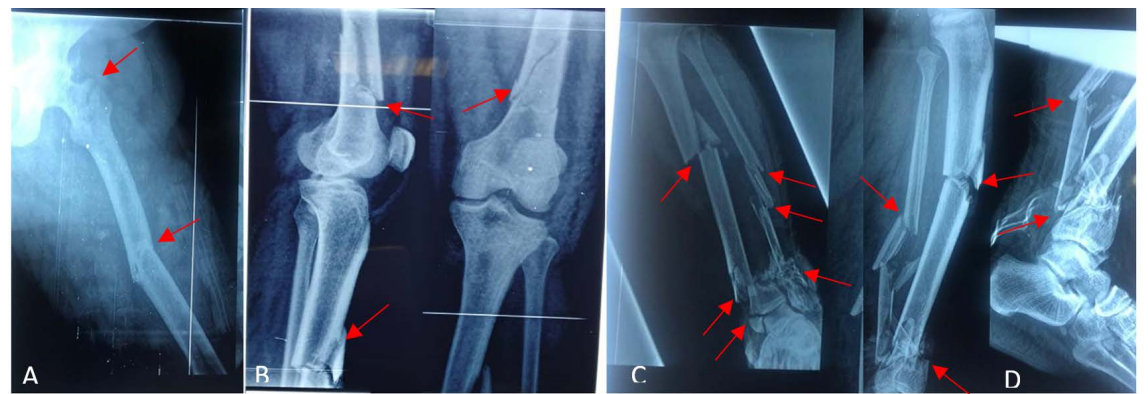

Figure 1. Multiple segmental fractures of lower limb.

in its distal third and finally, an open fracture of the medial malleolus (GA IIIB). The Mangled Extremity Severity Score (MESS) was rated at 6.

Emergency management consisted of fluid resuscitation amongst which was blood transfusion, chest drainage and DCO consisting: debridement of all open fractures, reduction and external fixation of the fracture (Figure 2A) and pertrochanteric screwing (Figure $2 \mathrm{~B}$ ). The patient was immediately put on triple parenteral antibiotic therapy (Cefuroxime 1, $5 \mathrm{~g} / 24 \mathrm{~h}$, Metronidazole $1.5 \mathrm{~g} / 24 \mathrm{~h}$ for 06 weeks, Gentamycin $240 \mathrm{mg} / 24 \mathrm{~h} 5$ days $/ 7$ for 3 weeks) and iterative debridements were performed. We did not observe any post-operative infection. Internal osteosynthesis was planned from the 14th post-operative day but due to lack of financial resources, they could not be performed.

The evolution at the 8th post-operative week was marked by the installation and progressive aggravation of left lower limb edema, resistant to postural drainage, massage therapy and physiotherapy.

At the 3rd month after surgery, the patient was discharged against medical advice and did not return for outpatient consultations until 10 months later. On clinical examination, he had a voluminous edema of the entire left lower limb (Figure 3), shiny, hard, and non-pitting, with a positive Stemmer sign. The Doppler performed in the lower limbs revealed a stasis of lymphatic origin without arterial or venous abnormality in favour of chronic lymphedema of the lower left limb. In addition, there was an aseptic segmental non-union, complicated with an infraction of the proximal femur and distal half of the tibia (Figure 4). We performed a transfemoral amputation during which intraoperative findings were amyotrophy with significant adipose degeneration and bone cyanosis of the amputation stump (Figure 5). The post-operative follow-up was normal. With physicotherapy, he walked with a pair of crutches after four weeks.

\section{Discussion}

Multiple segmental fractures are serious lesions whose management is complex and the evolution is full of imminent risks of complications. In the developing countries, they result from high-energy traumas, with road traffic accidents ranking first [1] [2] [3] [4]. The involvement of motorcycles and non-compliance to the driving code contribute to the violence of trauma and the occurrence of serious injuries [1] [2]. Our patient, a bike rider, was violently hit by a vehicle in 


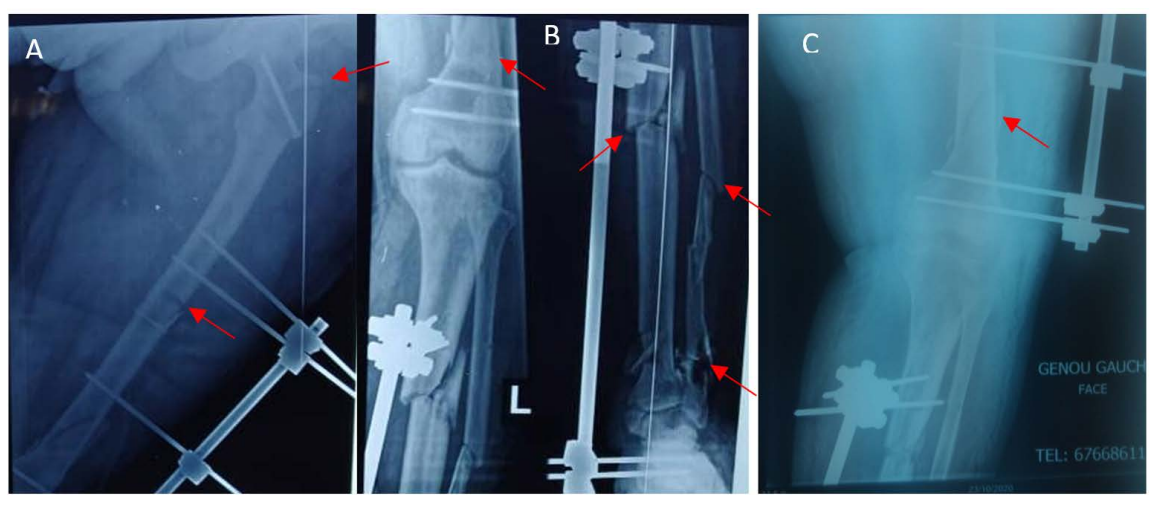

Figure 2. Good alignment of multiple fractures on the control X-rays after the Damage Control Orthopaedic.

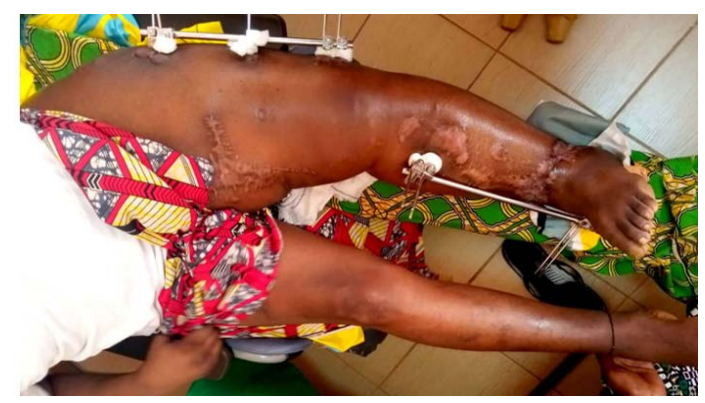

Figure 3. Severe chronic post-traumatic lymphoedema of left lower limb.

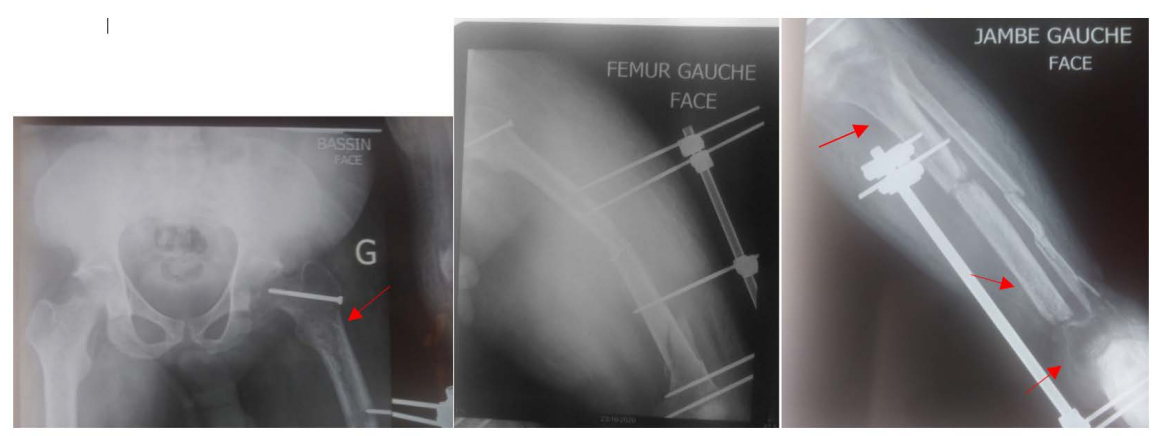

Figure 4. Non-union of differents fractures with osteopenia of the proximal femur, osteolysis of distal quarter of the leg, thinning of the corticals and medullary heterogeneity corresponding to segmental bone infarction.

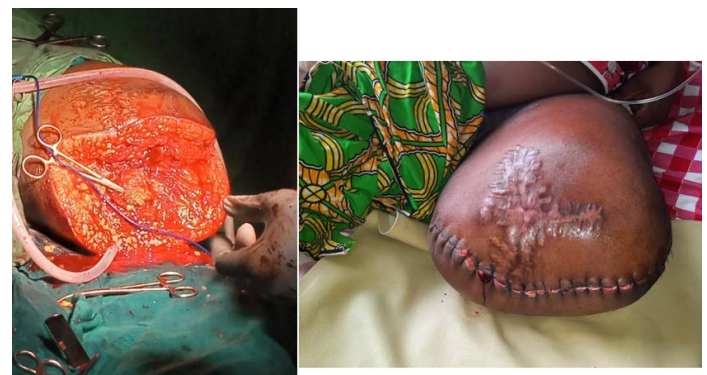

Figure 5. Amyotrophy, increased adipose panicle and oedematous infiltration of tissues intraoperatively. 
high speed. The subsequent trauma involved his entire left side of the body: head, chest, hip, femur, leg and ankle. The complexity of bone lesions sustained is noted with the difficulty of applying common classifications such as Frazer in floating knees or $\mathrm{AO}$ in segmental long bones fractures. We opted for a radiological description, lesion by lesion. The treatment of all these lesions, initiated in the context of the DCO could not be followed by the secondary more stable osteosynthesis recommended to the patient, for lack of financial resources and health insurance. This two-staged surgical strategy is recommended by other authors [8] [9]. In the absence of these, our patient underwent a prolonged period of bed rest of three months, during which all measures to prevent lymphedema proved insufficient including physiotherapy performed by our experienced professionals. Post-operative lymphedema is a transient acute condition whose transition to chronicity can be prevented by decongestive physiotherapy, the gold standard treatment [5]. The crowding of our patient's lower limb by external fixators and bandages probably contributed to his chronic lymphoedema by limiting manual lymphatic drainage in quality and quantity aspects. Associated factors such as the localisation of the laceration at the anterior medial aspect of the proximal $1 / 3$ rd of the thigh, with underlying lymph nodes and vessels, as reported by some authors [5] [10]. Regarding bone infarctions, the radiological diagnosis was made late when the patient returned, almost a year later. This unexpected complication, combined with multiple bones non-union of the limb and the patient's poverty posed a real therapeutic problem. Faced with this observation, a palliative amputation was performed. A primary amputation could have been considered [11] in the face of the violence of the trauma, the multiple segmental fractures of the lower limb, the significant attrition of the soft tissues and the poor economic power of the patient. However, the MESS score below 7 and the patient's refusal justified conservative treatment.

\section{Conclusion}

Although rare, chronic lymphedema and bone infarction are secondary complications of long bones fractures to be known, prevented, searched and treated early, particularly in patients with multiple segmental fractures. The failure of these precautions could adversely affect the functional prognosis of the limb and lead to dramatic amputation, especially in developing countries.

\section{Declarations}

All authors have contributed, read and approved this manuscript. The authors stated that they have no conflicts of interest. This manuscript is not submitted to any other journal. The consent of the patient was obtained to report his case.

\section{Conflicts of Interest}

The authors declare no conflicts of interest regarding the publication of this paper. 


\section{References}

[1] Ibrahima, F., Fokam, P., Douala, M.S. and Bahebeck, J. (2011) Trauma of the Musculoskeletal System in Cameroon. About 456 Cases Observed during 5 Years at Douala General Hospital. Health Sciences and Disease, 12, 12-18.

[2] Ngaroua, D., Mbo, A., Aidego, N., Djibrilla, Y. and Eloundou, J. (2016) Fractures Due to Road Accidents at Ngaoundere Regional Hospital, Cameroon. Health Sciences and Disease, 17, 24-28.

[3] Amossou, F., Padonou, A., Guidi, E., Chigblo, P., Lawson, E., Madougou, S., HansMoevi, A., et al. (2019) Epidemiological and Lesional Profile of Multiples Limbs Fractures at the Departmental Teaching Hospital of Oueme-Plateau (DTHOP) of PortoNovo. Journal de la Société de Biologie Clinique, 30, 54-58.

[4] Handy, E.D., Léopold, L., Bayiha, J.E., Essomba, O.D.L., Ngo, N.B., Farikou, I. and Jean, B. (2016) Concomitant Injuries to Floating Knees and Gravity. The Pan African Medical Journal, 25, 83-87.

[5] Ndiaye, M., Diadie, S., Dioussé, P., Diatta, B.A., Diop, A., Dione, M.A., Kane, A., et al. (2020) The Causes of Member's Lymphoedema: A Retrospective Study of $309 \mathrm{Ca}$ ses in Dakar. Our Dermatology Online, 11, 1-6. https://doi.org/10.7241/ourd.2020S.1

[6] Fimbo, A.M., Minzi, O., Mmbando, B.P., Barry, A., Nkayamba, A.F., Mwamwitwa, K.W., Aklillu, E., et al. (2020) Prevalence and Correlates of Lymphatic Filariasis Infection and Its Morbidity Following Mass Ivermectin and Albendazole Administration in Mkinga District, North-Eastern Tanzania. Journal of Clinical Medicine, 9, 1550. https://doi.org/10.3390/jcm9051550

[7] Pijnenburg, L., Felten, R. and Javier, R.M. (2019) A Review of Avascular Necrosis, of the Hip and Beyond. La Revue de Médecine Interne, 41, 27-36. https://doi.org/10.1016/j.revmed.2019.10.332

[8] Pape, H.C., Giannoudis, P. and Krettek, C. (2002) The Timing of Fracture Treatment in Polytrauma Patients: Relevance of Damage Control Orthopedic Surgery. The American journal of surgery, 183, 622-629. https://doi.org/10.1016/S0002-9610(02)00865-6

[9] Guerado, E., Bertrand, M.L., Cano, J.R., Cerván, A.M. and Galán, A. (2019) Damage Control Orthopaedics: State of the Art. World Journal of Orthopedics, 10, 1-13. https://doi.org/10.5312/wjo.v10.i1.1

[10] Tomson, D., Lessert, C., Klumbach, D., Mazzolai, L. and Depairon, M. (2012) In Prevention of Lymphatic Disorders and Their Complications. Revue Médicale Suisse, 8 , 315-319.

[11] Tampe, U., Weiss, R.J., Stark, B., Sommar, P., Al Dabbagh, Z. and Jansson, K.Å. (2014) Lower Extremity Soft Tissue Reconstruction and Amputation Rates in Patients with Open Tibial Fractures in Sweden during 1998-2010. BMC Surgery, 14, Article No. 80. https://doi.org/10.1186/1471-2482-14-80 